\title{
Multidisciplinaridade e especificidade na comunicação científica: discussão do impacto na avaliação de diferentes áreas ${ }^{1}$
}

\section{Rogério Mugnaini}

Estatístico, mestre em Ciência da Informação pela Pontifícia Universidade Católica de Campinas e doutor em Ciência da Informação pela Escola de Comunicações e Artes (ECA/ USP). Professor de Gestão de Políticas Públicas da Escola de Artes, Ciências e Humanidades da Universidade de São Paulo (EACH-USP), área de concentração de Métodos Quanti-tativos e Políticas Públicas e docente do Programa de Pós-Graduação em Ciência da Informação da ECA-USP.

mugnaini@usp.br

\section{Dinah Apparecida de Melo Aguiar Población} Professora da Universidade de São Paulo, bibliotecária com especialização em Ciência da Informação pela Universida-de de São Paulo. Mestre em Ciências da Comunicação e doutora em Ciências da Comunicação pela Universidade de São Paulo. Pós-doutorado pela Universidad Autonoma de Madrid. Áreas de interesse: Cientometria, Documentos da Área da Saúde. pobla@terra.com.br

\author{
DOI: $10.3395 /$ reciis.v4i4.426pt
}

\begin{abstract}
Resumo
As referências bibliográficas podem revelar o perfil da ciência publicada, oferecendo importantes informações sobre a história de uma revista. Ao identificar o impacto dos diferentes tipos de documentos citados por cinco revistas científicas de áreas diversas, constatou-se que o livro é consideravelmente mais citado numa revista de Ciências Sociais Aplicadas, enquanto a área de Saúde Coletiva faz uso deste tipo de documento em proporções equiparáveis com os artigos científicos. Nas revistas de Física e Medicina as citações a revistas internacionais são muito mais prevalentes. E na revista de Veterinária e de Ciência da Informação, destacam-se os anais e teses. Estas constatações são importantes para entender as culturas de comunicação científica das áreas, o que pôde ser observado também ao analisar, tanto as classificações das revistas no Qualis, quanto os critérios constantes dos documentos de área. Indicadores bibliométricos não restritos a um índice são capazes de oferecer parâmetros para cooperar na definição de critérios para avaliação da produção científica brasileira, segundo as características das diferentes áreas do conhecimento.
\end{abstract}

\section{Palavras-chave}

Comunicação científica; Indicadores bibliométricos; Avaliação; Bases de dados; Citação.
A crescente tendência de utilização de indicadores bibliométricos para avaliação de produção científica sinaliza a necessidade de discussões que tragam luz, não apenas à metodologia envolvida, mas também aos conceitos que os mesmos se propõem a mensurar.

O conceito de "impacto científico", que normalmente é associado a "qualidade de investigação", é atribuído a um documento publicado, quando citado posteriormente em outras publicações. As bases de dados de revistas se consolidaram como principal fonte de informação para mensuração de impacto e, conseqüentemente, o impacto da publicação é transferido ao autor, ao departamento, à universidade, à cidade, ao estado e/ou ao país onde o mesmo foi gerado, propiciando as mais diversas análises comparativas de desempenho acadêmico.
Estes indicadores, muitas vezes enfocados de forma isolada e independente das especificidades de cada área, resultam em rankings de consistência obviamente questionável. Tomando como exemplo um ranking de impacto de países no Science Citation Index (da Thomsom Reuters - antigo Institute for Scientific Information-ISI), baseado nas citações aos artigos publicados pelos pesquisadores de cada país (GIBBS, 1995), pode-se analisar, percorrendo as diversas etapas da comunicação científica, as fontes de inconsistência presentes em cada uma delas.

1. Citações recebidas - As razões de citar são diversas, não indicando necessariamente qualidade, ou importância da pesquisa (BONZl et al., 1991; WEST et al., 2002), estando limitada pela possibilidade de acesso do autor citante à literatura da temática em estudo. 
2. Base de dados - O escopo de uma base de dados determina a probabilidade de citação (MACROBERTS, 1996), uma vez que se destina a um público de interesse, de acordo com a coleção existente, e esta, por sua vez pode ser constituída de documentos que diferem em tipo, área do conhecimento, idade, distribuição, entre outras características.

3. Revistas - As revistas constituem o produto resultante do agrupamento dos artigos selecionados para publicação, diferindo não apenas em quantidade de artigos publicados num mesmo ano, mas também nas formas subjetivas de seleção de artigos, avaliados por diferentes grupos de pessoas, com pontos de vista e culturas certamente díspares (DAVYT et al., 2000).

4. Artigos-Oartigo científico busca apresentar a maior e mais atualizada informação sobre o tema pesquisado e inseri-lo na publicação que represente o meio mais adequado de comunicação com seus pares. No entanto, suas conclusões podem variar de acordo com a metodologia adotada, a fonte de dados utilizada e outras escolhas feitas em cada etapa da investigação.

5. Autor - $\mathrm{O}$ autor de um trabalho pode ser o único responsável pelo trabalho, assim como co-autor, podendo nem sequer saber interpretar os resultados encontrados (GARCIA, 2007). Sua participação em um projeto, ou num determinado programa de pós-graduação dependerá de diversas características curriculares, assim como de seu posicionamento político, dentro e além de seu campo científico (BOURDIEU, 1994).

6. Linha de pesquisa - A pesquisa realizada em um departamento dependerá não apenas dos interesses dos seus integrantes, assim como do financiamento que receberá, segundo a relevância do que se pretende estudar, frente à comunidade científica da área temática a que pertence, mas também frente aos demais departamentos da mesma universidade e a política em suas diversas instâncias (pessoal, institucional, etc.) (POBLACIÓN et al., 2006).

7. Área do conhecimento - As diferentes áreas e suas respectivas práticas de comunicação científica diferem significativamente, assim como o desenvolvimento de seu corpus teórico.
8. Universidade - A excelência de uma universidade ou instituto de pesquisa, conquistada por meio da pesquisa desenvolvida ao longo dos anos pode ser atribuída automaticamente à produção dos seus pesquisadores (ESCOBAR, 2007), independente da continuidade da excelência alcançada por seus diversos departamentos.

9. País - A mensuração da atividade científica de um país não se restringe à pesquisa publicada, muito menos àquela constante dos artigos de revistas.

10. Política científica - A agenda de pesquisa e a avaliação, definidas em nível nacional, determinam os temas e os veículos, direcionando a publicação e influenciam diretamente o processo de comunicação científica (MUGNAINI, 2006).

Os diversos desvios possíveis nas diversas etapas do fluxo da comunicação científica podem sugerir que a soma de todos esses vieses poderia invalidar totalmente um indicador bibliométrico, uma vez que o mesmo não logra oferecer uma estimativa fidedigna do fenômeno estudado. Desta forma, estudos bibliométricos devem garantir uma quantidade suficiente de dados para que apresente resultados consistentes.

Segundo a Teoria da Probabilidade, a lei dos Grandes Números garante que, sob certas hipóteses, que a realização de $n$ repetições independentes de uma variável aleatória, fará com que a média aritmética dessas $n$ observações se aproximará da probabilidade real daquele fenômeno. Para exemplificar, ao se lançar uma moeda não-viciada, a probabilidade real de se obter "cara" é 0,5. Porém, o resultado final dos primeiros dez lançamentos pode resultar em sete vezes cara, ou seja, probabilidade de 0,7. Dessa forma, o que esta lei afirma, é que quanto maior a repetição deste experimento, maior a aproximação da probabilidade real.

O nível de agregação considerado numa análise bibliométrica pode revelar ou esconder importantes descobertas que os dados podem proporcionar, devendo-se considerar também que, quanto menor o nível de agregação, mais significativos são os efeitos dos erros no resultado final. A concepção dos indicadores de produção científica deve priorizar maiores volumes de informação, correspondentes a períodos mais representativos, e que abranjam maior diversidade de tipos de documento.

Os indicadores bibliométricos vêm sendo tomados, crescentemente, como parâmetros de avaliação da produção 
científica nacional, sendo normalmente obtidos de bases de dados que limitam à produção publicada em artigos de revistas científicas. O Journal Citation Reports (JCR) é uma fonte de indicadores que se consolidou, e sua utilização como fonte única de dados se deve principalmente à facilidade de acesso e à credibilidade alcançada, uma vez que é disponibilizada há mais de três décadas. Este feito, que por um lado tem permitido a utilização destes indicadores durante todos esses anos, por outro, consolidou o Fator de Impacto como principal indicador, mesmo com as diversas inconsistências exaustivamente descritas na literatura (GARFIELD, 2006; ARCHAMBAULT et al., 2007).

Atualmente o desenvolvimento de grandes repositórios de informações científicas acessíveis online, permite a obtenção e análises de fontes complementares que diminuem as limitações inerentes ao uso restrito dos indicadores do JCR (MUGNAINI, 2006). Fontes alternativas começam a emergir como o Google Scholar, onde se pode recuperar e mensurar impacto, através de, não apenas de citações provenientes de revistas, mas de diversos tipos de documentos, desde que os conteúdos se encontrem disponíveis na rede (MUGNAINI et al., 2008). Todas estas questões são evidenciadas diretamente na política científica nacional, que lança mão de fontes consolidadas e conhecidas, e crescentemente passa a considerar outras fontes complementares, à medida que cada área as toma por consenso. Este tipo de constatação pode ser feito ao analisar os documentos de área das diversas áreas que compõem o Qualis, sistema de avaliação dos Programas de Pós-Graduação coordenado pela Capes (Coordenação de Aperfeiçoamento de Pessoal de Nível Superior).

Este trabalho toma algumas revistas científicas de áreas diversas, e analisa a importância das fontes de informação e dos diferentes tipos de documentos citados nos volumes de uma década. Dessa maneira, analisa a informação consumida pelos artigos como indicador capaz de oferecer parâmetros para cooperar na definição de critérios para avaliação da produção científica brasileira, segundo as características das diferentes áreas do conhecimento. E por fim, compara os resultados com os critérios que compõem o Qualis, de acordo com as áreas nas quais as revistas são avaliadas.

\section{Metodologia}

A base SciELO foi tomada como fonte de dados por apresentar uma coleção multidisciplinar, cuja metodologia permite identificar os tipos de documentos citados pelos artigos das revistas que indexa (SciELO, 2010).

Primeiramente foi selecionada a Revista de Saúde Pública, que era a revista com a coleção mais completa na base, permitindo a análise de um período de quatro décadas (1967-2006), desde seu primeiro fascículo. Além disso, a área de Saúde Coletiva é um exemplo em que o livro e a revista são tipos de documento de grande importância para sua comunidade acadêmica, diferindo de outras áreas aonde o valor do livro como veículo de publicação vem sendo desconsiderado, como se pode observar nos critério de avaliação de diversas áreas, segundo o Qualis (CAPES, 2010a).

Para representação de outras áreas, foram tomadas quatro revistas de diferentes áreas temáticas, segundo classificação do Portal de Periódico da Capes: Medicina Geral (Revista da Associação Médica Brasileira), Física (Brazilian Journal of Physics), Medicina Veterinária (Pesquisa Veterinária Brasileira) e Ciência da Informação (Ciência da Informação). Tal seleção considerou principalmente a disponibilidade de dados na última década, de modo a permitir confronto com a Revista de Saúde Pública (1997-2006). Certamente outras revistas de mesma área podem apresentar, tanto resultados similares, quanto totalmente díspares, o que poderia ser verificado em estudo posterior, não sendo um aspecto relevante neste momento.

As referências bibliográficas constantes do conjunto de fascículos de um ano completo foram identificadas, segundo os diversos tipos de documentos citados. Esse método foi possível devido à estruturação dos registros de citação da SciELO². Primeiramente procedeu-se a comparação das cinco revistas no período de dez anos, seguindo-se a análise do período de quarenta anos da Revista de Saúde Pública, subdivididos em oito qüinqüênios.

Do total de 116.426 referências de 5.355 artigos foi identificada a tipologia dos documentos: anais, tese, livro (completo, capítulo e outros tipos de monografia) e revista (segundo indexação na SciELO e/ou ISI, demais revistas brasileiras e outras revistas não identificadas ${ }^{3}$ ). Para identificação de títulos como indexados nas bases SciELO ou ISI considerou-se a coleção SciELO atual e as versões 19982004 do JCR, não importando o ano do documento citado4.

Finalmente, buscou-se confrontar as características das revistas com os critérios de avaliação do Q u a I i s, segundo as diversas áreas de avaliação, e o grau de importância atribuído a cada tipo de documento, por cada uma das áreas (CAPES, 2010a).

\section{Resultados}

A análise da distribuição das referências bibliográficas, segundo os tipos de documento, mostra as características da 
literatura priorizada nos artigos das revistas de cada área. Em outras palavras, esta análise revela a informação consumida para a argumentação desenvolvida nos artigos da revista. Podendo-se dizer que se trata de uma análise da revista, por meio da ciência sobre a qual ela está fundamentada, importando conseqüentemente, conhecer as fontes da informação citada.

Tendo em vista os critérios de avaliação da produção científica nacional, que valorizam a publicação em revistas indexadas, principalmente nas bases do ISI, é de se esperar que artigos publicados naquelas bases sejam citados, tanto nas revistas lá indexadas, como nas revistas nacionais presentes numa base nacional.

Um questionamento que direcionou esta análise, pelo fato das diversas áreas apresentarem características específicas, no que diz respeito às fontes citadas, foi a forte dependência de indicadores de impacto, cujo cálculo se baseia estritamente em citações recebidas de artigos. Ao se analisar as bases de dados de revistas, percebe-se que outros tipos de documento têm grande relevância para a literatura publicada nas revistas de diferentes áreas. Mugnaini, Meneghini e Packer (2007), num estudo também baseado em revistas indexadas na SciELO, mostra que as áreas tendem a priorizar um tipo de documento, destacando-se das demais. Na Figura a seguir, resultante de uma Análise Estatística Multivariada, onde os pontos representam áreas, e os eixos diagonais os tipos de documento citados, pode-se observar a associação entre eles, indicada pela proximidade entre eixos e pontos no plano.

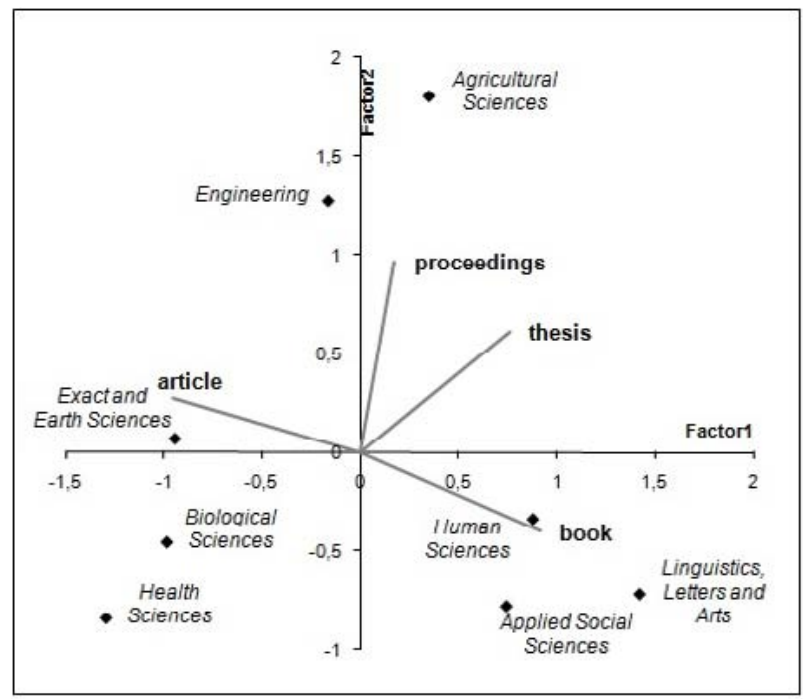

Figura - Análise Fatorial entre área citante e tipo documento citado - ano base 2004.
Nos Gráficos 1 e 2, as citações a revistas são representadas por listras paralelas; os efeitos pontilhados dizem respeito aos livros; e a literatura cinzenta (anais e teses) é identificada pelos tons cinzas (quadriculados). De forma geral pôde-se observar que as revistas apresentam características similares àquelas apresentadas por suas áreas de classificação, como ilustra a Figura 1.

As citações feitas pelas revistas Revista da Associação Médica Brasileira, Brazilian Journal of Physics e Pesquisa Veterinária Brasileira, mostraram que os artigos de revistas representam mais que $75 \%$ da informação consumida. As mesmas revistas mostram presença predominante de revistas indexadas no ISI, sugerindo uma pesquisa claramente pautada na literatura publicada em revistas internacionais.

Uma particularidade da Física é a presença de citações a "outras revistas", ou seja, revistas não indexadas que devem corresponder a artigos de repositórios de acesso aberto - área pioneira neste modelo de comunicação científica, desde 1991.

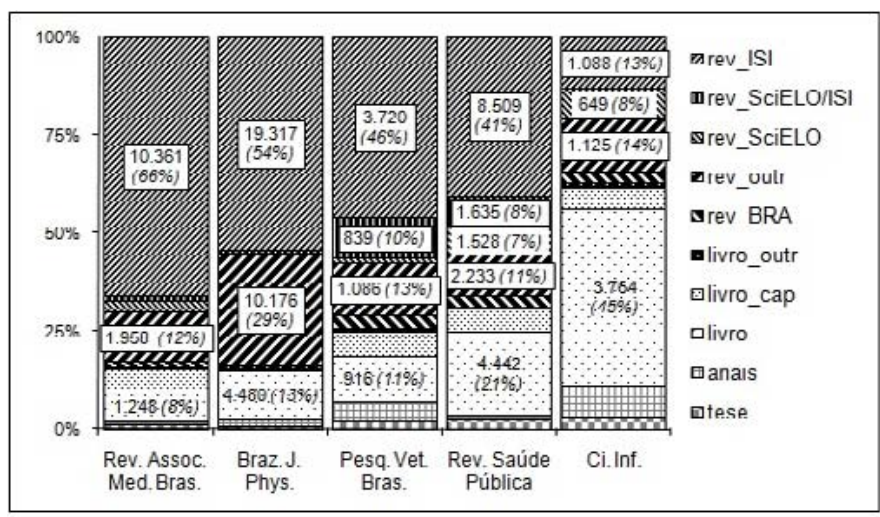

Gráfico 1 - Distribuição das referências bibliográficas decenais de revistas de diferentes áreas, segundo tipo de documento citado - período 1997-2006.

A área de Medicina Veterinária se destaca das demais pela citação a revistas SciELO/ISI, já que importantes revistas brasileiras desta área se encontravam indexadas também na SciELO desde aquele período.

Já a revista de Ciência da Informação revela a importância do livro para esta área, ao mesmo tempo em que preza pelos documentos publicados em anais. Pode-se observar que é a revista que tem suas citações mais distribuídas aos diversos tipos de documento.

Os capítulos de livro representam em torno de 6\% da literatura citada de todas as revistas, com exceção apenas da 
revista de Física, que também mostra presença quase nula das revistas nacionais (SciELO e demais revistas brasileiras). Outra observação importante é que revistas ISI não são as mais representativas no montante de citações a revistas.

A disponibilidade de 40 anos da Revista de Saúde Pública na SciELO permite a observação da consistência de indicadores baseados em grandes quantidades de informação, uma vez que podem ser observadas nítidas tendências ao longo dos qüinqüênios (Figura 3). Um aumento contínuo da porcentagem de citações a revistas ISI é identificado a partir da década de 90, o que pode se dever ao acesso às revistas dessa base, que é cada vez mais facilitado pelas iniciativas do governo brasileiro, e pelas tecnologias de informação online nos últimos anos.

A presença das revistas SciELO mostrou-se praticamente constante no período, tendo apresentado um aumento mais significativo nos anos de 2005 e 2006, que pode ter sido estimulado pela possibilidade de recuperação dos artigos através do Google, a partir deste período. Paralelamente, observa-se a diminuição de citações a "outras revistas" e a revistas brasileiras, o que denota a crescente importância das revistas indexadas.

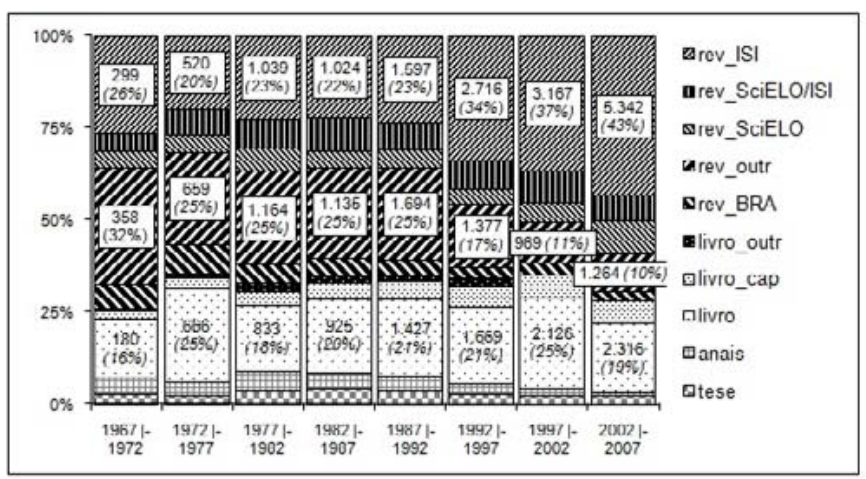

Gráfico 2 - Distribuição das referências bibliográfica qüinqüenais da Revista de Saúde Pública, segundo tipo de documento citado - período 1967-2006.

As classificações que as revistas recebem no Qualis são apresentadas na tabela na próxima página, onde, às qualificações da revistas nas diversas áreas, foram atribuídos pontuações $(A 1=7 ; A 2=6 ; B 1=5 ; B 2=4 ; B 3=3 ; B 4=2$; $\mathrm{B} 5=1 ; \mathrm{C}=0)$.

A Revista de Saúde Pública é qualificada em 30 áreas, seguida da Brazilian Journal of Physics (20 áreas), Pesquisa Veterinária Brasileira (18 áreas), Revista da Associação Médica Brasileira (17 áreas) e Ciência da Informação (13 áreas).
As áreas mais próximas à temática de cada revista estão sinalizadas em vermelho, nota-se que as revistas de Física e Medicina encontram-se menos qualificadas em suas próprias áreas do que as demais revistas. O fato das revistas de Ciência da Informação, Veterinária e Saúde Pública terem revelado menor tendência à literatura internacional em suas citações, sinalizava um "lugar" mais privilegiado para as mesmas na avaliação da área. Para as demais revistas observa-se o contrário, podendo-se observar ainda que são as únicas que recebem ao menos uma qualificação $C$.

Outra comparação explicativa resultante da avaliação de cada uma dessas revistas pode ser feita a partir das médias e medianas das pontuações que as revistas receberam nas diversas áreas. Apresentam-se na seguinte ordem decrescente, com a Revista de Saúde Pública mais bem qualificada, com média e mediana superiores à menos qualificada, Revista da Associação Médica Brasileira.

Considerando que os estratos que cada revista ocupa nas diversas áreas são determinados pelos critérios de avaliação, segundo o documento de cada área, resta analisálos, tomando para tanto as principais áreas de cada revista (sinalizadas em vermelho na Tabela 1).

Na Tabela 2 pode-se observar que as fontes de informação são determinantes da qualificação em diversas áreas. O JCR, constante dos critérios das áreas de Ciências Exatas e da Terra, Agrárias e Saúde desde o triênio anterior, passa a ser utilizado nas Ciências Sociais Aplicadas no triênio atual, o que pode se dever ao expressivo número de revistas brasileiras que entraram na base nos últimos três anos.

A exemplo da recente adoção do JCR pelas Ciências Sociais, outras bases de dados vão sendo tomadas pelas diversas áreas, como é o caso da Scopus, SciELO, e inúmeras bases específicas de cada área. Porém, os indicadores oferecidos pelas mesmas leva algum tempo para serem adotados, o que é compreensível, uma vez que os indicadores têm maior consistência à medida que a cobertura temática vai se consolidando em determinada base, pelo ingresso das revistas da área. Uma iniciativa de destaque é o portal de Periódicos Eletrônicos de Psicologia (PePSIC), que consiste de uma base composta de revistas latino-americanas - nem todas as revistas da coleção conseguiram ingressar na SciELO, contudo adotaram a metodologia para constituição de um índice de citação da área. Indício da importância que esta fonte vem tomando é o próprio fato de figurar entre as fontes adotadas nos critérios de avaliação da área de Saúde Coletiva.

O Fator de Impacto é o único indicador que já vem sendo parâmetro da avaliação das áreas com maior tendência 
\begin{tabular}{l|l|l|l|l|l} 
Revista & Braz. J. Phys. & Ci. Inf. & Pesq. Vet. Bras. & Rev. Assoc. Med. Bras. Rev. Saúde Pública
\end{tabular}

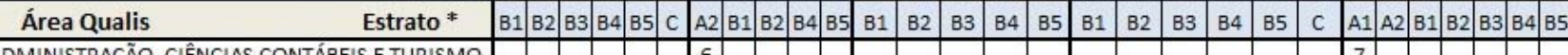
ADMINISTRAÇÃO, CIÊNCIAS CONTÁBEIS E TURISMO ANTROPOLOGIA / ARQUEOLOGIA

ASTRONOMIA / FÍSICA BIOTECNOLOGIA

CIÊNCIA DA COMPUTAÇ̃̃O

CIÊNCIA DE ALIMENTOS

CIÊNCIA POLÍTICA E RELAÇÕES INTERNACIONAIS

CIÊNCIAS AGRÁRIAS I

CIÊNCIAS BIOLÓGICAS I

CIÊNCIAS BIOLÓGICAS II

CIÊNCIAS BIOLÓGICAS III

CIÊNCIAS SOCIAIS APLICADAS I

DIREITO

ECOLOGIA E MEIO AMBIENTE

ECONOMIA

EDUCAÇ̃̃O

EDUCAÇÃO FÍSICA

ENFERMAGEM

ENGENHARIAS I

ENGENHARIAS II

ENGENHARIAS III

ENGENHARIAS IV

ENSINO DE CIÊNCIAS E MATEMATICA

FARMÁCIA

FILOSOFIA/TEOLOGIA:subcomissão TEOLOGIA

GEOCIÊNCIAS

GEOGRAFIA

HISTÓRIA

INTERDISCIPLINAR

LETRAS / LINGUÍSTICA

MATEMÁTICA / PROBABILIDADE E ESTATÍSTICA

MATERIAIS

MEDICINA I

MEDICINA II

MEDICINA III

MEDICINA VETERINÁRIA

ODONTOLOGIA

PLANEJAMENTO URBANO E REGIONAL / DEMOGRAFI PSICOLOGIA

QUIMIICA

SAÚDE COLETIVA

SERVIÇO SOCIAL

SOCIOLOGIA

ZOOTECNIA / RECURSOS PESQUEIROS

\begin{tabular}{c} 
Média \\
\hline Mediana
\end{tabular}

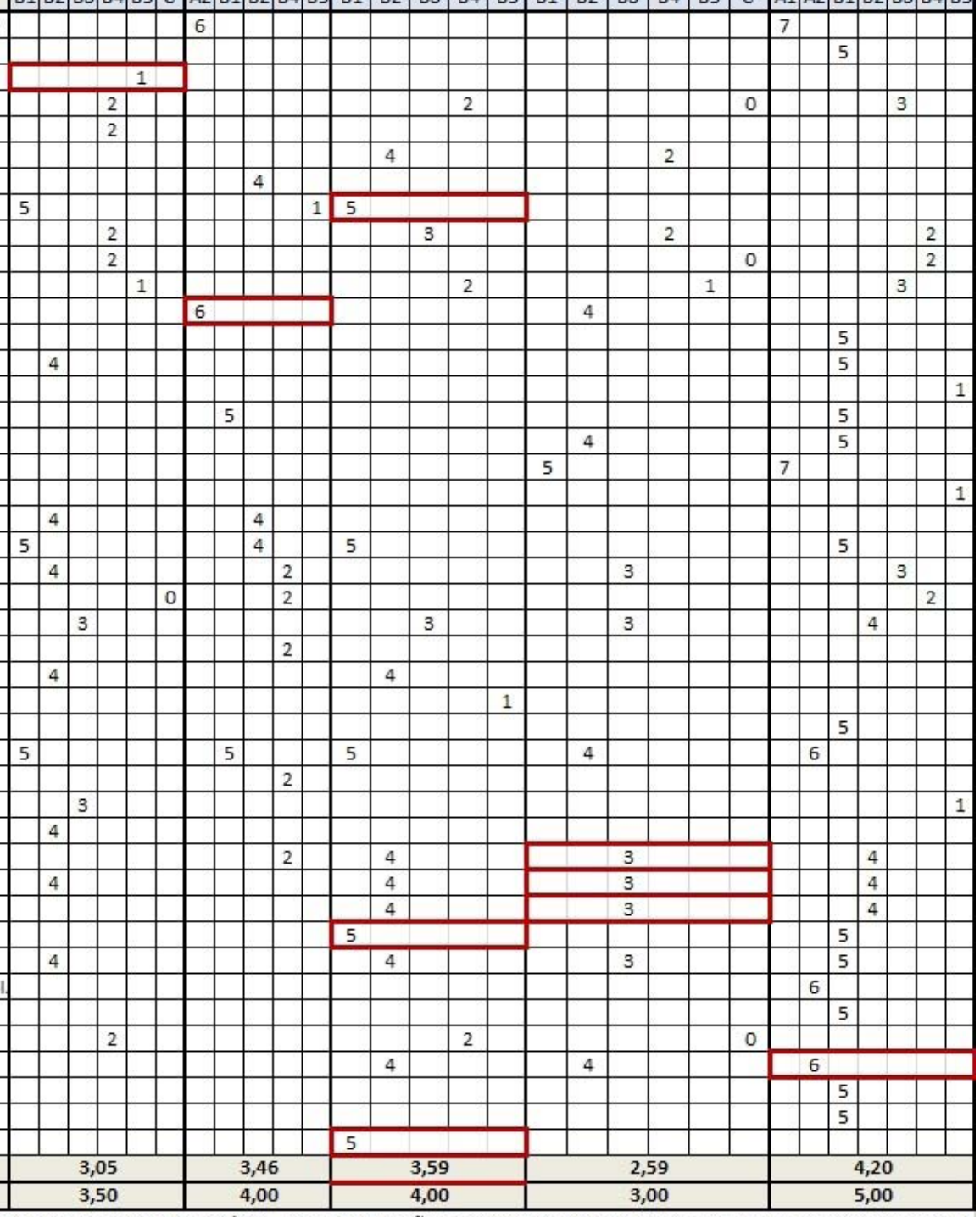

- Revistas classificadas duas vezes (versões online e impressa) em alguma área, normalmente são classificadas no mesmo estrato, sendo raros os casos onde há diferenciação - por exemplo, a Revista de Saúde Pública é recebe classificações B1 e B4 da área ENGENHARIAS III, para as versões impressa e online, respectivamente - tomando, nestes casos, a melhor classificação.

Tabela 1 - Classificação das revistas segundo Área de Avaliação e Estrato Qualis - triênio 2007-2009.

internacional. Nota-se que apenas a revista Ciência da Informação não o toma como parâmetro. Por outro lado, a área de Saúde Coletiva prioriza o índice h das revistas na Scopus, recorrendo ao Fator de Impacto JCR se a mesma não é indexada na Scopus. Destaca-se a valorização da base SciELO, nesta área, determinante para classificação no segundo estrato de maior valor (A2), o que vai de encontro com a análise da citações da Revista de Saúde Pública. Cabe mencionar um trecho do documento desta área, que expressa a importância das revistas nacionais:
No campo da Saúde Coletiva, ao longo dos anos, houve a consolidação de vários periódicos publicados no país. Eles vêm ganhando crescente reconhecimento internacional, tanto no que diz respeito à indexação e citação, quanto ao recebimento de contribuições oriundas de outros países. (CAPES, 2010b)

E finalmente, nota-se que as áreas de Saúde Coletiva e Ciências Sociais Aplicadas I atribuem peso menor (40\%) aos artigos de revistas, no quesito Produção Intelectual, quando da avaliação dos Programas de Pós-Graduação. Este 


\begin{tabular}{|c|c|c|c|c|c|}
\hline Revista & Grande Área (CNPq) & $\begin{array}{l}\text { Grande Área } \\
\text { (CNPq) }\end{array}$ & $\begin{array}{l}\text { Critérios: } \\
\text { fontes de informação e indica dores }\end{array}$ & $\begin{array}{l}\text { Roteiro para } \\
\text { classificação de } \\
\text { Livro? }\end{array}$ & $\begin{array}{l}\text { Peso atribuido a } \\
\text { artigos em revis ta na } \\
\text { Produção Intelectual }\end{array}$ \\
\hline Braz. J. Phys. & ASTRONOMIA / FÍSICA & $\begin{array}{c}\text { Ciências Exatas e } \\
\text { da Terra }\end{array}$ & Fator de Impacto (JCR) & กล̃o & 50 \\
\hline Ci. Inf. & $\begin{array}{l}\text { CIÊNCIAS SOCIAIS } \\
\text { APLICADASI }\end{array}$ & $\begin{array}{c}\text { Ciências Sociais } \\
\text { Aplicadas }\end{array}$ & $\begin{array}{l}\text { Indexação no JCR, Scopus, SciELO, } \\
\text { entre outras bases da área }\end{array}$ & $\operatorname{sim}$ & 40 \\
\hline \multirow{3}{*}{ Pesq. Vet. Bras. } & CIÊNCIAS AGRÁRIASI & \multirow{3}{*}{ Ciências Agrárias } & \multirow{3}{*}{$\begin{array}{c}\text { Fator de Impacto (JCR); } \\
\text { Indexação na Scopus, SciELO, entre outras } \\
\text { bases daárea }\end{array}$} & กล̃o & 55 \\
\hline & MEDICINA VETERINÁRIA & & & กão & 55 \\
\hline & $\begin{array}{l}\text { ZOOTECNIA / RECURSOS } \\
\text { PESQUEIROS }\end{array}$ & & & $\operatorname{sim}$ & 55 \\
\hline \multirow{3}{*}{$\begin{array}{l}\text { Rev. Assoc. Med. } \\
\text { Bras. }\end{array}$} & MEDICINA I & \multirow{4}{*}{$\begin{array}{l}\text { Ciências da } \\
\text { Saúde }\end{array}$} & \multirow{3}{*}{$\begin{array}{c}\text { Fator de Impacto (JCR); } \\
\text { Indexação no Medline, SciELO, } \\
\text { entre outras bases da área }\end{array}$} & กล̃o & 50 \\
\hline & MEDICINA II & & & กล̃o & 50 \\
\hline & MEDICINA III & & & กão & 50 \\
\hline Rev. Saúde Pública & SAÚDE COLETNA & & $\begin{array}{l}\text { Índice h (SClmago-Scopus); } \\
\text { Fator de Impacto (JCR), se não está na Scopus; } \\
\text { SCIELO, desdeo nivel A2; } \\
\text { PEPSIC, desde o nivel B3 }\end{array}$ & Sim & 40 \\
\hline
\end{tabular}

Tabela 2 - Critérios de avaliação das revistas - documentos da área do Qualis, triênio 2007-2009.

cenário também pode ser previsto ao se analisar as citações das revistas da área, conforme apresentado no Gráfico 1.

\section{Conclusões}

A proposição de indicadores, ou de critérios para avaliação das revistas, pode originar-se com uma análise mais detalhada das mesmas. Nesse sentido, as referências bibliográficas podem revelar um perfil da ciência publicada, capaz de oferecer importantes informações sobre a história de uma revista, ou, num nível de agregação mais amplo, de uma área.

A metodologia aplicada permitiu identificar o destaque a diferentes tipos de documentos, segundo as citações das revistas analisadas, provenientes das diferentes áreas científicas. $\mathrm{O}$ livro é consideravelmente mais citado numa revista de Ciências Sociais Aplicadas que em revistas de Ciência da Saúde. Já a área de Saúde Coletiva faz uso deste tipo de documento em proporções equiparáveis com os artigos científicos. Nas revistas de Física e Medicina as citações a revistas internacionais são muito mais prevalentes. E na revista de Veterinária e de Ciência da Informação, destacam-se os anais e teses.

Estas constatações são importantes para entender as culturas de comunicação científica das áreas, o que pôde ser observado também ao analisar, tanto as classificações das revistas no Qualis, quanto os critérios constantes dos documentos de área.

O fato das técnicas e ferramentas bibliométricas ainda não terem sido vulgarizadas suficientemente, faz com que simples análises descritivas das citações das revistas, como desenvolvido neste estudo, não sejam conhecidas pelos pesquisadores que compõem as comissões da avaliação orquestrada pela Capes. Contudo, independente disso, nota-se forte semelhança entre os critérios e as citações. Por outro lado, o uso deste tipo de informação poderia enriquecer os critérios de avaliação, para que não se limitem a um único indicador.

\section{Notas}

1. Pesquisa financiada pelo CNPq (processo no 483095/2009-5)

2. O acesso se deu diretamente à base de dados SciELO, que se encontra em formato ISIS (Integrated Scientific Information System), em sistema operacional Linux, estruturada em diversos tipos de registros individuais, que contêm campos específicos para armazenamento da informação. Os diferentes tipos de registros são: fascículos; artigos, que são armazenados em diversos registros separadamente, contendo informações bibliográficas sobre o artigo publicado. Além disso, cada referência da bibliografia do artigo tem seu respectivo registro, estruturado de acordo com o tipo de documento citado, possibilitando portanto a identificação dos mesmos. Estatísticas destes campos estão disponíveis em diversas tabelas em formato Microsoft Excel, para todas rede SciELO (países e temáticos) em <http://www.scielo.org/php/level.php?lang=pt\&component=56 \&item=27>. Acesso em:21 dez. 2010.

3. O procedimento de padronização de títulos citados reconhece, dentre as revistas não identificadas como ISI e/ou SciELO, títulos brasileiros, no entanto, dentre as "outras revistas não identificadas" podem restar títulos brasileiros não localizados na base ISSN (fonte de informação do país de publicação).

4. Ou seja, a leitura dos resultados deve considerar que foram identificadas as citações a revistas ISI citadas há alguns anos atrás, mesmo que no ano citado, a revista não estivesse incluída ainda naquela base. 


\section{Referências}

ARCHAMBAULT, E.; LARIVIÈRE, V. Origins of measures of journal impact: historical contingencies and their consequences on current use. In: INTERNATIONAL CONFERENCE OF THE INTERNATIONAL SOCIETY FOR SCIENTOMETRICS AND INFORMETRICS, 11, 2007, Madrid. Anais... Madrid: CINDOC-CSIC, 2007. p.45-50. Disponível em: <http://citeseerx.ist.psu.edu/viewdoc/download?doi= 10.1.1.95.3835\&rep=rep $1 \&$ type $=p d f>$. Acesso em: $10 \mathrm{fev}$. 2010.

BONZI, S.; SNYDER H.W. Motivation for citation: comparison of self citation and citation to others. Scientometrics, v.21, p.245-254, 1991.

BOURDIEU, P. El campo científico. Redes. Revista de estudios sociales de la ciencia, v.1, n.42, p.131-160, 1994.

CAPES. QUALIS, BBS (site). Disponível em: <http://qualis. capes.gov.br>. Acesso em: 30 nov. 2010a.

CAPES. Documento de área 2009: saúde coletiva. Disponível em: <http://qualis.capes.gov.br/arquivos/avaliacao/ webqualis/criterios2007_2009/Criterios_Qualis_2008_22. pdf>. Acesso em: 30 nov. $2010 b$.

DAVYT, A.; VELHO, L. A avaliação da ciência e a revisão por pares: passado e presente como será o futuro? História, Ciências, Saúde - Manguinhos, v.7, n.1, p.93-116, 2000. [doi: 10.1590/S0104-59702000000200005]

ESCOBAR, H. Produção científica cresce mais de 200\% nas grandes universidades. O Estado de São Paulo, 1, ago. 2007. A-13.

GARCIA E.S. Borboletas da ciência: olho neles. Jornal da Ciência, v.21, n.601, p. 12, 2007.

GARCIA-ZORITA, J. C. La actividad científica de los economistas españoles, en función del ámbito nacional o internacional de sus publicaciones: estudio comparativo basado en un análisis bibliométrico durante el período 1986-1995. Espanha. 2000. 405f. Tese (Doutorado em Documentação) - Universidad Carlos III de Madrid, Madrid, 2000.
GARFIELD, E. The history and meaning of the journal impact factors. JAMA, v.295, n. 1, p.90-93, 2006.

GIBBS, W. W. Lost science in the third world. Scientific American, v.273, n.2, p.76-83, 1995.

MACROBERTS, M. H.; MACROBERTS, B. R. Problems of citation alysis. Scientometrics, v.36, n.3, p.435-444, 1996.

MUGNAINI, R. Caminhos para adequação da avaliação da produção científica brasileira: impacto nacional versus internacional. São Paulo, 2006. 253f. Tese (Doutorado em Ciência da Informação) - Escola de Comunicações e Artes, Universidade de São Paulo, São Paulo. 2006. Disponível em: $<$ http://www.teses.usp.br/teses/disponiveis/27/27151/tde11052007-091052/publico/TESE_mugnaini_r.pdf>. Acesso em: 10 fev. 2010.

MUGNAINI, R. ; MENEGHINI, R. ; PACKER, A. L. . Citation profiles in Brazilian journals of the SciELO database in different scientific areas. In: INTERNATIONAL CONFERENCE OF THE INTERNATIONAL SOCIETY FOR SCIENTOMETRICS AND INFORMETRICS, 11, 2007, Madrid. Anais... Madrid: CINDOCCSIC, 2007. v. II. p. 904-905.

MUGNAINI, R.; STREHL, L. Recuperação e impacto da produção científica na era google: uma análise comparativa entre $\mathrm{O}$ google acadêmico e a web of science. Encontros Bibli, v.13, p.92-105, 2008. Disponível em: <http://www.doaj.org/doaj ?func=fulltext\&passMe=http://www.periodicos.ufsc.br/index. php/eb/article/view/1127/1570>. Acesso em: 10 fev. 2010.

POBLACIÓN, D.A.; OLIVEIRA, M. Input e output: insumos para o desenvolvimento da pesquisa. In: POBLACION, D.A.; WITTER, G.P.; SILVA, J.F.M. (Orgs.). Comunicação e produção científica: contexto, indicadores e avaliação. $1^{\text {a }}$ ed. São Paulo: Angellara, 2006, p.57-79.

SciELO. Indicadores bibliométricos da rede SciELO. Disponível em: <http://www.scielo.org/php/level.php?lang=pt\&compon ent $=56 \&$ item $=27>$. Acesso em: 30 nov. 2010.

WEST, R.; McILWAINE, A. What do citation counts count for in the field of addiction? an empirical evaluation of citation counts and their link with peer ratings of quality. Addiction, v.97, p.501-504, 2002. 